\title{
CORRUPTION IN THE TIMES OF PANDEMIA
}

\author{
Jorge Gallego \\ Mounu Prem \\ Juan F. Vargas
}

\section{LATIN AMERICAN AND THE CARIBBEAN ECONOMIC ASSOCIATION}

May 2020

The views expressed herein are those of the authors and do not necessarily reflect the views of the Latin American and the Caribbean Economic Association. Research published in this series may include views on policy, but LACEA takes no institutional policy positions.

LACEA working papers are circulated for discussion and comment purposes. Citation of such a paper should account for its provisional character. A revised version may be available directly from the author.

(C) 2020 by Jorge Gallego, Mounu Prem and Juan F. Vargas. All rights reserved. Short sections of text, not to exceed two paragraphs, may be quoted without explicit permission provided that full credit, including (C) notice, is given to the source. 
LACEA WORKING PAPER SERIES No. 0044 May 2020

Corruption in the times of Pandemia

Jorge Gallego

Universidad del Rosario, School of Economics

jorge.gallego@urosario.edu.co

Mounu Prem

Universidad del Rosario, School of Economics

francisco.munoz@urosario.edu.co

Juan F. Vargas

School of Economics, Universidad del Rosario

juan.vargas@urosario.edu.co

\section{ABSTRACT}

The public health crisis caused by the COVID-19 pandemic, coupled with the subsequent economic emergency and social turmoil, has pushed governments to substantially and swiftly increase spending. Because of the pressing nature of the crisis, public procurement rules and procedures have been relaxed in many places in order to expedite transactions. However, this may also create opportunities for corruption. Using contract-level information on public spending from Colombia's e-procurement platform, and a difference-in-differences identification strategy, we find that municipalities classified by a machine learning algorithm as traditionally more prone to corruption react to the pandemic-led spending surge by using a larger proportion of discretionary non-competitive contracts and increasing their average value. This is especially so in the case of contracts to procure crisis-related goods and services. Our evidence suggests that large negative shocks that require fast and massive spending may increase corruption, thus at least partially offsetting the mitigating effects of this fiscal instrument.

JEL Classification: H57, H75, D73, I18.

Keywords: Corruption, COVID-19, Public procurement, Machine learning.

\section{ACKNOWLEDGEMENTS AND FINANCIAL DISCLOSURE}

Erika Corzo and Andrés Rivera provided excellent research assistance. We thank Luis Martínez for sharing with us his data on corruption. 


\section{INTRODUCTION}

The COVID-19 pandemic, caused by the SARS-CoV-2 novel coronavirus, has rapidly expanded throughout the world, creating an unprecedented public health crisis in both developed and developing countries (Ferguson et al., 2020). In an effort to control the spread of the disease, many governments in different regions have established stringent lockdown measures, restricting the mobility of millions of citizens and paralyzing the operation of a large fraction of companies across multiple sectors of the economy (Acemoglu et al., 2020; Ludvigson et al., 2020). These lockdowns have hit developing countries particularly hard. There, a considerable proportion of the population derive their livelihood from informal activities, most of which cannot be executed remotely and that lack any access to safety nets such as unemployment insurance (Loayza and Pennings, 2020; Mobarak and Barnett-Howell, 2020). Consequently, in addition to the large investments in medical infrastructure and related supplies that governments have had to make to face the health crisis, a large part of the budget has been allocated to meet the economic needs of the most poor and vulnerable, as well as to help survive small and medium businesses that are more vulnerable to large periods of economic inactivity. In this paper, we show that the need of governments to quickly spend large amounts of resources may create corruption opportunities in public procurement.

Simplification of public procurement protocols in order to expedite transactions has been a widespread consequence of the pandemic (De Michele and Cruz, 2020). Traditional norms governing public contracting generally require, at least for purchases greater that a certain value, lengthy and thorough procedures. These seek to limit the discretion of public officials and promote competition among sellers in order to avoid potential collusion between bureaucrats and contractors. With the objective of streamlining spending decisions in the midst of the current health emergency, the governments of countries such as Argentina, Australia, Brazil, Canada, Chile, Colombia, France, Germany, Hungary, Israel, New Zealand (just to mention a few) have eased their public procurement regulation over the past weeks. ${ }^{1}$ However, there is widespread evidence that lessening controls increases discretionary spending and thus generate more opportunities for malfeasance (Transparency International, 2010; CAF, 2019). This situation may be particularly entrenched in places that have traditionally had low levels of state capacity and high levels of corruption, creating a vicious circle that makes it difficult to provide adequate emergency care.

\footnotetext{
${ }^{1}$ To track emergency legislation around the world see: https://www.lexology.com/library/detail.aspx?g=d75c6657a3f7-4312-b341-7ba8da835fd8 (last accessed on May 12, 2020).
} 
In this paper, we provide evidence of this phenomenon using data on public procurement in Colombia and weekly longitudinal variation across the country's roughly 1,100 municipalities. ${ }^{2}$ Our difference-in-differences identification strategy exploits the timing of the first detected case of COVID-19 in the country, as well as the cross-sectional variation provided by the baseline probability that a municipality is corrupt. Specifically, we test for differential changes in procurement decisions across municipalities once the pandemic hits the country. A major challenge of our empirical strategy is to classify municipalities according to their baseline latent corruption likelihood. To that end, we use an ensemble model that aggregates the corruption predictions of four canonical machine learning algorithms: random forest, gradient boosting machine, lasso, and neural network. For the predictions we use observed cases of corruption prosecutions from 2008 to 2015, as collected by Martinez (2019) using information from the Office of the Inspector General of Colombia, and up to 147 municipality-level predictors, grouped into ten categories and measured for the same period.

We find that, after the outbreak of COVID-19 in Colombia, places that rank higher on our predicted baseline corruption scale differentially increase the use of discretionary contracts, which are awarded using a direct selection procedure and allow for no competition whatsoever among bidders. A one-standard-deviation increase in the predicted baseline probability of corruption increases the probability of awarding a discretionary contract in 5 percentage points, a $7 \%$ increase with respect to the pre-COVID-19 period weekly mean. We also find that, after the outbreak, an increase of the same magnitude in predicted corruption increases the average value of a discretionary contract by $7.5 \%$. Finally, using text-analysis techniques, we identify the subset of contracts that were awarded to buy crisis-related goods and services, such as food and medical supplies. For these contracts, we find that after the first detected COVID-19 case in Colombia, a one-standarddeviation increase in the predicted baseline probability of corruption increases the average value of a crisis-related contract by $7 \%$, with most of the effect coming from food-related items (a $13 \%$ increase), which are easier to over-price.

The results are robust to different specifications and alternative explanations, and we also provide further evidence supporting our claims. For instance, we find that the differential effect of the outbreak on discretionary spending in corrupt municipalities is higher after the President released a decree that enabled local governments to relax their procurement procedures. Additionally, our results remain unchanged if we control for the spread of the disease across the country. Moreover,

\footnotetext{
${ }^{2}$ Municipalities are the third administrative layer of the country, and are equivalent to counties in the U.S.
} 
we find that there is a null correlation between the number of cases and deaths caused by COVID-19 and municipality-level corruption. Hence, we can partially rule out the idea that the most corrupt places have been more affected by the disease, and accordingly, have had to adapt their procurement strategies more intensively than their less corrupt counterparts. Our results are also robust to the inclusion of a control that captures municipalities' access to ports and markets, thus suggesting that the results are not driven by corrupt places facing more difficulties and higher prices in the acquisition of crisis-related items.

To be sure, while compelling, our quantitative evidence is only suggestive. Because its illegal nature, objectively measuring corruption is challenging (Olken, 2007; Olken and Pande, 2012; Fisman, 2001). We rely on the fact that more discretionary and less competitive procurement generates graft opportunities (see CAF (2019) for a recent review and Gallego et al. (2019) for empirical evidence that discretion in public procurement is one of the main determinants of corruption), but do not have a smoking gun that could be used as evidence in court. However, recent extensive anecdotal evidence that we discuss in section 2 provides strong support to our interpretation that procurement rules relaxations in response to the crisis have lead to more corruption.

This paper contributes to the literature studying the governance challenges imposed by catastrophic events, such as natural disasters and epidemics (Khemani, 2020). One strand of the literature has studied the political economy of epidemics, focusing on how these events relate to and affect political outcomes. Studies have focused on different dimensions, such as electoral behavior (Beall et al., 2016; Adida et al., 2019; Campante et al., 2020), state legitimacy (Fluckiger et al., 2019), women empowerment (Bandiera et al., 2019), and conflict (Gonzalez-Torres and Esposito, 2017). More related to our findings, Maffioli (2020) finds that in Liberia the government's response to the Ebola outbreak was strategic in such a way that relief efforts were not allocated efficiently but privileged electorally swing villages. We contribute to this literature by showing that public health crises, like the one caused by the COVID-19 pandemic, may affect other important political outcomes, such as corruption, which importantly makes recovery slower and more difficult.

Another strand of literature has studied the connection between disasters and corruption. Some authors argue that disaster relief may be allocated strategically to win elections (Garret and Sobel, 2003; Gasper and Reeves, 2011), even in a clientelistic fashion (Gallego, 2018). Other show that natural disasters create resource windfalls that may trigger corruption and fraud (Leeson and Sobel, 2008; Nikolova and Marinov, 2017). In general, the argument is that catastrophic events imply the 
mobilization of resources in the form of relief, which may be strategically appropriated by political actors. We delve deeper into the channels explaining corruption in the midst of a catastrophe, by showing how relief spending differentially changes as a function of historical corruption. We also show that not only foreign aid is at risk (Andresen et al., 2020), but also other forms of public resources.

Finally, our paper is connected to the vast literature on corruption, by providing an objective measure of malfeasance and by exploring some of the economic consequences of this phenomenon. ${ }^{3}$ In line with previous research (Gallego et al., 2019; Colonnelli et al., 2020), we construct an objective measure based on observable characteristics and a machine learning approach. This measure allows us to the disentangle the effects of corruption on public procurement in the midst of an emergency.

This paper is composed of five sections, including this Introduction. In Section 2 we describe the Colombian context, emphasizing on the emergency legislation that has simplified public procurement in the midst of the emergency. Section 3 describes the data we use and our identification strategy, underscoring the way in which we construct the municipality-level corruption index, the contract-level information gathered from Colombia's e-procurement platform, and the differencein-differences approach used to identify the results. These are reported in Section 4, and Section 5 concludes.

\section{Context}

The first detected case of COVID-19 in Colombia was announced on March 6th, 2020, corresponding to a 19-year old woman that had recently traveled back from Milan, Italy. The virus has spread at a lower pace compared to other countries in the region, such as Brazil, Ecuador, or Peru, perhaps due to the rapid response from the central government. By April 27, the last day included in our analysis, a total of 5,597 people had tested positive and 253 had officially died from the disease. 180 municipalities, out of the 1103 in the country, had reported cases by then. Panel A of Figure A1 in the Appendix reports the temporal evolution of cases in Colombia.

Soon after the first case was detected, President Ivan Duque announced a series of measures to contain the spread of the disease and to mitigate its economic impact, which became apparent after a nationwide lockdown which began on March 24, 2020 and the end of which has been repeatedly

\footnotetext{
${ }^{3}$ For reviews, see Banerjee et al. (2012), Olken and Pande (2012), and Fisman and Golden (2017), and see Colonnelli
} and Prem (2020) for recent evidence on the economic costs of corruption. 
extended through April and May. On March 17, Duque appealed article 215 of the Constitution to declare an "economic and social emergency" in the country, which allowed the executive to issue emergency decrees. Shortly afterwards, the National Public Procurement Agency (Colombia Compra Eficiente, CCE) issued an official statement clarifying the implications of the emergency on public procurement and inviting contracting entities, (including local governments) to invoke instances of manifest urgency to speed up procurement when necessary. This entitled officials to directly select contractors without any previous bidding stage in order to expedite the procurement of goods and services considered necessary to face the emergency. ${ }^{4}$ However, as we show in this paper, the relaxation of public procurement rules also promotes the very activities that the rules were designed to discourage to begin with, namely corruption and malfeasance.

Indeed, a few weeks after the state of emergency was invoked by the president, Colombia's control agencies - the Comptroller General, the Inspector General, and the Attorney General-revealed that several local and regional governments were taking advantage of the situation by likely engaging in corruption. These organization released a list of a handful of mayors and governors that awarded suspicious contracts, in which overcosts were apparent. For instance, in one such case, revealed by the Office of the Comptroller General, authorities in the town of La Palma had bought rice at a price almost $10 \%$ higher than the market price, chocolate with a $44 \%$ price premium and chlorine bleach with a $330 \%$ price premium. ${ }^{5}$ In Arauca, cans of tuna were bought at a prices over five times the market value and soap was bought at 4.5 times its regular price. ${ }^{6}$ The data journalism unit of La Silla Vacía, a Colombian independent news website, studied a sample of 48 contracts awarded in 17 departments in the midst of the emergency. ${ }^{7}$ The report found overprices in more than $40 \%$ of the contracts analyzed, with food items such as sugar cane paste, salt, pasta, rice, beans, oil, sugar, and lentils being where the highest premiums were found.

\footnotetext{
${ }^{4}$ The statement literally establishes that "even though the public tender is the awarding mechanism that constitutes the general rule for entities governed by the General Statute of Procurement of the Public Administration (...) Law 1150 of 2007 establishes some exceptions to free competition and to the plurality of bidders" (p. 1). See CCE's statement here:

https://www.colombiacompra.gov.co/sites/cce_public/files/cce_documentos/comunicado_covid_19.pdf (last accessed May 12th, 2020).

${ }^{5}$ See https://www.pulzo.com/nacion/cuarentena-alcalde-palma-explica-sobrecostos-contrato-mercados-PP877697 (last accessed May 11th, 2020).

${ }^{6}$ See https://forbes.co/2020/04/08/actualidad/contralor-denuncia-sobrecostos-de-80-000-millones-en-ayudas-porcovid-19-en-el-pais/ (last accessed May 11th, 2020).

${ }^{7}$ Departments are equivalent to U.S. states.
} 


\section{DATA AND EMPIRICAl STRATEGy}

\subsection{Data.}

3.1.1. Public procurement. Public procurement data used for this paper comes from the Sistema Electrónico para la Contratación Pública (SECOP), a web-based platform established by the Colombian government to digitize transactions held by public entities in the country. The first version of the platform, SECOP I, was created simply to publicize procurement but it recently evolved into SECOP II, a site where transactions can actually take place online. Compliance with the regulation that mandates the use of SECOP has increased over time since its creation and its usage is currently quite comprehensive. Today, the platform details approximately 10 million contracts from national and subnational-level public entities. ${ }^{8}$

For this analysis, we focus on contracts held by local-level governments from January 1 to April 27 of 2020 , covering a total of 357,875 contracts with a total value of US\$ 4.5 billion. Contract-level information includes important features such as the total budget of the contract, its approval date and duration, a unique standard identifier (UNSPCSC code), a textual description of the good or service under contract, the nature of the contracting agency (national or subnational) and the type of process that was used in the procurement among other. The type of process refers to the awarding instruments available for agencies, including public tenders, selection based on the qualification of merits, auctions, special regime, minimum-value, and direct selection. Importantly, the direct selection procedure is the least competitive mechanism, and its use is legally restricted to special cases, including situations of manifest urgency caused by particular events such as natural disasters. In turn, the textual description of each contract's purpose allows us to use text-analysis techniques to identify which contracts correspond to crisis-related spending. In particular, using a dictionary method, we identify all contracts related to the procurement of food and health-related goods and services. ${ }^{9}$

We thus have access to fine-grained information on public spending at the municipality-week level and for the different awarding instruments used by local governments. This allows us to confidently track whether a specific municipality used the direct selection method (and for what value), in a particular week of 2020, and if such a contract corresponded to the procurement of a crisis-related

${ }^{8}$ See https://www.datos.gov.co/Gastos-Gubernamentales/SECOP-Integrado/rpmr-utcd (last accessed May 12th, 2020).

${ }^{9}$ For the food category we used the Spanish words "alimentos", "víveres", "comida", "mercados", "kits", while for health-related procurement, we used the words "médico", "salud", "medicamentos", "hospitalización", "farmacia". 
good or service. Figure A1 in the Appendix presents the evolution of discretionary contracts-i.e. those awarded through the direct selection method - as a share of the sum of discretionary and competitive contracts, both for the total number of contracts and the amount awarded by these. ${ }^{10}$

3.1.2. Corruption. Measuring corruption is challenging (Olken, 2007; Olken and Pande, 2012). More so measuring corruption for all the districts of a particular country. ${ }^{11}$ Rather than relying on perceptions of citizens or key actors - a common approach to measure corruption championed by international organizations - we follow Gallego et al. (2019) and Colonnelli et al. (2020) and use a machine learning approach to predict corruption based on factual corruption detections and observable characteristics of municipalities.

Using information from the Office of the Inspector General of Colombia and originally collected by Martinez (2019), we construct a dummy variable indicating if the mayor of each municipality was prosecuted by this anticorruption agency in the 2008-2011 or 2012-2015 mayoral periods. We define this measure as our outcome variable and combine it with a large set of municipal characteristics to train several machine learning models: random forest, gradient boosting machine, lasso, and neural network. $^{12}$ We ensemble these using (Polley et al., 2011)'s super learner approach to construct a municipal-level risk score in each of the two periods. We use a random $70 \%$ of our dataset to train the models, and the remaining $30 \%$ to test their performance. ${ }^{13}$ We asses the predictive performance of our models in the testing set using conventional metrics, such as the Area Under the ROC curve (AUC) and accuracy. Overall, our ensemble model achieves a high level of performance, at an accuracy of 0.84 and a AUC of 0.71 . Given these numbers, we proceed to construct the corresponding predicted values for each municipality-period, which indicate the probability of being classified as corrupt. The final score for each municipality is the average of the two probabilities, one for each period. Figure 1 maps the baseline geographic distribution of predicted corruption in Colombia, according to our model.

Table A1 in the Appendix reports the descriptive statistics.

\footnotetext{
${ }^{10}$ We define 'competitive' contracts that are awarded using public tenders, auctions, selection based on merits, or a special regime, as they imply potential competition between two or more bidders.

${ }^{11}$ Ferraz and Finan (2008) and subsequent paper by the same authors measure corruption using the results of public audits in Brazil, that are only available for a subset of municipalities. In the case of Colombia, Transparencia por Colombia (2017) produced an index that focused on 28 department capitals.

${ }^{12}$ We use a total of 147 municipality-level predictors, grouped into ten categories and measured for the same period as the outcome. The categories are: financial sector, conflict, crime, human capital, local politics, public sector, local demographics, economic activity, illegal activity, and natural resources.

${ }^{13}$ We use a 5-fold, 10-time repeated cross-validation procedure to train our models and choose the optimal combination of parameters. In the case of the super learner the optimal weights used by the ensemble are 0.25 for the random forest, 0.26 for the boosting machine, 0.02 for the neural network, and 0.47 for the lasso.
} 


\subsection{Empirical strategy.}

3.2.1. Main specification. Our identification strategy exploits the timing of the first detected case of COVID-19 in Colombia (March 6th, 2020), as well as the cross-sectional variation provided by the baseline probability of a municipality being corrupt. More formally, using the subindex $m$ to denote municipalities and $t$ to denote weeks, we estimate the following difference-in-differences model:

$$
y_{m t}=\alpha_{m}+\lambda_{t}+\beta\left(\text { Post Outbreak }_{t} \times \text { Corrupt }_{m}\right)+\sum_{c \in X_{m}} \gamma^{\prime}\left(c \times \lambda_{t}\right)+\epsilon_{m t}
$$

where $y_{m t}$ are different measures of public procurement in municipality $m$ in week $t$; Corrupt $_{m}$ is a standardized measure of the predicted probability of corruption described in Section 3.1.2; Post Outbreak $_{t}$ is a dummy that takes the value one after March 6th, 2020; and $X_{m}$ is a set of municipality-level characteristics measured in 2019 that include total population, population density, and a poverty index. We interact these characteristics with the week fixed effects, $\lambda_{t}$, to allow for differential flexible trends parametrized by these municipality features. Additional to the week fixed effects, we include municipality fixed effects, $\alpha_{m}$, that control for any observed or unobserved municipal-level time invariant heterogeneity. In turn, the non-interacted week dummies control for any time shock that affects simultaneously all the municipalities on the same week. Finally, $\epsilon_{m t}$ is the error term. Given that our treatment variable, Corrupt, is the result from the predicted values of a previously-estimated model, we estimate wild bootstrap standard errors that are clustered at the municipality level.

Our coefficient of interest, $\beta$, captures the average differential change in the use of discretionary public procurement contracts, before and after the the outbreak of COVID-19 in municipalities with a high estimated baseline probability of corruption, relative to municipalities with a low estimated probability. In order to measure the use of discretionary contracts, for the outcome $y_{m t}$ we focus on a dummy variable indicating whether a contract was awarded using the direct selection procedure in municipality $m$ and in week $t$, and the natural log of the average amount of money awarded through this procedure. We also focus on discretionary contracts associated to crisis-related spending, in particular to procure food and health-related services and supplies.

3.2.2. Identifying assumption. The main assumption behind our empirical model is that in the absence of the outbreak of COVID-19, the usage of discretionary public procurement contracts in 
municipalities with a high estimated baseline probability of corruption would have followed a similar trajectory to the usage of discretionary public procurement contracts in municipalities with a low estimated probability. The validity of this "parallel trends" assumption can be partially assessed by estimating the following non-parametric regression:

$$
y_{m t}=\alpha_{m}+\lambda_{t}+\sum_{j \in J} \beta_{j}\left(\text { Corrupt }_{m} \times \delta_{t}\right)+\sum_{c \in X_{m}} \gamma^{\prime}\left(c \times \lambda_{t}\right)+\varepsilon_{m t}
$$

where $\mathrm{J}$ includes all weeks in our sample except from the week before the first COVID-19 case in Colombia. Therefore, the parameters $\beta_{j}$ can be interpreted as the differential usage of, for example, discretionary public procurement contracts in municipalities with a high predicted probability of corruption relative to municipalities with a low probability, in week $j$, relative to the week prior to the first detected COVID-19 case in the country.

\section{Results}

Table 1 presents the main results from specification (3.1). We include municipality and week fixed effects throughout, as well as by the interaction of the latter with baseline controls. The dependent variable in Columns 1 to 3 is the indicator of that least one discretionary contract was awarded in municipality $m$ and week $t$. In Columns 4 to 6 we focus on the (log) value of discretionary contracts. We find that, after the first COVID-19 case in Colombia, there is a differential increase in the probability of using a discretionary contract in municipalities with higher predicted baseline probability of corruption. Focusing on Column 1, a one-standard-deviation increase in the predicted probability of corruption increases the probability of a issuing discretionary contract in 5 percentage points (pp.), which represents an increase of $7 \%$ with respect to the average in the pre-COVID-19 period. Moreover, we find that the average value of a contract increased by $7.5 \%$ (see Column 4).

In addition, Columns 2 and 5 control for the municipal prevalence of the disease by including the number of COVID-19 cases. Controlling for the prevalence of the virus is arguably a 'bad control' but we still do so to make sure that our results are explained by the proclivity of engaging in corruption and not by the severity of the disease. The point estimates are largely robust to this control, suggesting that the intensity of the COVID-19 infection is not a likely channel. ${ }^{14}$ Overall,

\footnotetext{
${ }^{14}$ Furthermore, in Table A2 of the appendix we run a cross-sectional regression where the dependent variable is the number of COVID-19 cases (Column 1) and the number deaths associated with this disease (Column 2), while our treatment variable is the estimated baseline probability of corruption. We do not find any significant associated.
} 
these results support the idea that municipalities with a higher probability of corruption did not change their public procurement behavior due to the needs caused by the pandemia.

Finally, Columns 3 and 6 control for market access by including the distance of each municipality to the nearest port and the department capital interacted with the week fixed effects. We do this to test whether our results are explained by municipalities with a higher probability of corruption also finding it more difficult to access supplies, a channel which could explain the increase in the use and value of discretionary contracts. We do not find support for this alternative story: while the point estimate slightly fall in magnitude, they are not statistically different from our baseline coefficients.

Table A4 of the Appendix reports additional robustness tests. Columns 1 to 4 assess the robustness of our inference. Columns 1 and 2 follow Conley (1999) and Conley (2016) and control for cross-sectional dependence and first order time dependence in the error term. Columns 3 and 4 follow Bertrand et al. (2004) and collapse the data before and after the first COVID-19 case to deal with potential serial correlation in the dependent variable. Our results are robust to both these corrections. Furthermore, Columns 5 and 6 use the average observed corruption cases (instead of the machine-learning prediction) as the treatment variable. The coefficients remain positive but are slightly noisier (the p-value in Column 6 is 14\%). Finally, in Figure A3 we present the robustness to the exclusion of one department at a time, and we find coefficients to be stable to the exclusion of any department.

In Figure 2, we present the results from equation (3.2). In both panels we find no differential trends in the six weeks before the first COVID-19 case for municipalities with a higher predicted baseline probability of corruption relative to the ones with a lower probability. Overall, this evidence provides support for the main identifying assumption of our empirical strategy. ${ }^{15}$ Moreover, the figures suggest that, in contrast to the estimated (null) effects for the weeks prior to the first COVID-19 case in Colombia, after the arrival of the pandemic there is a differential increase in the usage and value of discretionary public procurement contracts in municipalities with a higher estimated baseline probability of corruption. Moreover, the effect grows over time.

We corroborate this pattern in a more parametric way, by splitting the post first-case period into two, taking into account the presidential decree that enabled municipalities to declare the manifest urgency to increase the use of discretionary contracts (March 17). In Table A3 of the Appendix, we

\footnotetext{
${ }^{15}$ Figure A2 in the Appendix report equivalent results for the alternative measure of observed corruption.
} 
include a post dummy that takes the value of one for weeks between the first case and the release of the presidential decree (Post 1), and a dummy that takes the value of one for weeks after the release of the presidential decree (Post 2). We find that for both of our main dependent variables there is a larger and statistically different effect after the relaxation of the requirements for the usage of discretionary contracts.

We then study whether the pattern encountered for discretionary contracts can be also found for competitive procurement, which limits the scope for graft and was also not directly affected by any presidential decree. This falsification is important for the validity of our results. We find that there is no differential usage in this type of contracts and that their average value does not differentially increase in more corruption-prone places after the first COVID-19 case (see Table A5 and Figure A5 in the Appendix).

Finally, if we group contracts distinguishing between crisis needs (food and health-related items) versus other contracts we find that after the first COVID-19 case, municipalities that are onestandard-deviation more likely to be corrupt at baseline experience an increase in the average value of crisis-related contract of $7 \%$ (see Column 1 of Table 2 and Figure A4). Moreover, when we separate the post COVID-19 period by taking into account the decree that encouraged the usage of discretionary contracts, the size of the effect doubles to $13 \%$ (Column 2). Using text analysis, we also split contracts between food and health-related and find that most of the effect is driven by a large increase in the value of food-related items in municipalities predicted to be more corrupt at baseline. A one-standard-deviation increase in the predicted corruption increases the value of these contracts after the presidential decree in $21 \%$ (Column 4). The observed increase in contracts that procure health-related items $(5 \%)$ is not statistically significant. These results go in line with the anecdotal and judicial evidence presented in Section 3.1.2, which suggests that malfeasance was mainly driven by cost overruns in the acquisition of food relief.

\section{Conclusion}

This paper studies the evolution of public procurement during the COVID-19 crisis in Colombia. Using the first case of COVID-19 as our time variation, and a machine learning-estimated baseline probability of corruption at the municipality level, we find that the spending rush led by the pandemic increases the usage and value of discretionary procurement contracts - which are more 
likely to be corrupt - in places initially more likely to be corrupt. We also show that these effects are higher after the relaxation of procurement requirements, and are more pronounced in the procurement of crisis-related items such as food.

Our findings have important policy implications. It is obvious that in the midst of a catastrophe, such as the COVID-19 pandemic, governments need to relax contracting procedures in order to guarantee the expedited procurement of relief and other crises-related items. However, in order to curb the potential negative effects of these policies in terms of graft, top-down accountability tools such as audits - which have proven effective in other contexts (Olken, 2007; Avis et al., 2018)should accompany the relaxation of contracting rules. More transparency, coupled with technology and data science, could also help reducing corruption. Our analysis exemplifies how machine learning techniques can be applied to the information provided by e-procurement platforms to identify places in which malfeasance is more likely to occur. In these contexts, preventing corruption may well save lives. 


\section{REFERENCES}

Acemoglu, D., V. Chernozhukov, I. Werning, And M. Whinston (2020): "A Multi-Risk SIR Model with Optimally Targeted Lockdown," Mimeo.

Adida, C., K. Dinone, And M. Platas (2019): "Ebola, elections, and immigration: how politicizing an epidemic can shape public attitudes," Politics, Groups, and Identities, 1-27.

Andresen, J., N. Johannsen, And B. Rijkers (2020): "Elite Capture of Foreign Aid: Evidence from Offshore Bank Accounts," World Bank Policy Research Paper no. 9150.

Avis, E., C. Ferraz, and F. Finan (2018): "Do Government Audits Reduce Corruption? Estimating the Impacts of Exposing Corrupt Politicians," Journal of Political Economy, 126, 19121964.

Bandiera, O., N. Buehren, M. Goldstein, I. Rasul, and A. Smurra (2019): "The Economic Lives of Young Women in the Time of Ebola: Lessons from an Empowerment Program," World Bank Working Paper.

Banerjee, A., S. Mullainathan, And R. Hanna (2012): "Corruption," Tech. rep., National Bureau of Economic Research.

Beall, A., M. Hofer, And M. Schaller (2016): "Infections and elections: Did an Ebola outbreak influence the 2014 US federal elections (and if so, how)?" Psychological Science, 27, 595-605.

Bertrand, M., E. Duflo, and S. Mullainathan (2004): "How much should we trust differences-in-differences estimates?" The Quarterly journal of economics, 119, 249-275.

CAF (2019): "2019 Report on Economic Development - Integrity in Public Policies: Keys to Prevent Corruption," Tech. rep., CAF-Development Bank of Latin America.

Campante, F., E. Depetris-Chauvin, and R. Durante (2020): "The Virus of Fear: The Political Impact of Ebola in the U.S." Mimeo.

Colonnelli, E., J. Gallego, and M. Prem (2020): "What Predicts Corruption?" Mimeo.

Colonnelli, E. And M. Prem (2020): "Corruption and Firms," Mimeo.

Conley, T. G. (1999): "GMM estimation with cross sectional dependence," Journal of Econometrics, 92, 1-45. (2016): Spatial Econometrics, London: Palgrave Macmillan UK, 1-9.

De Michele, R. And J. Cruz (2020): "How Transparency Can Save Lives in the Coronavirus Crisis," Americas Quarterly.

Ferguson, N., D. Laydon, G. Nedjati-Gilani, N. Imai, K. Ainslie, M. Baguelin, S. Bhatia, A. Boonyasiri, And Z. Cucunuba et AL. (2020): "Report 9: Impact of nonpharmaceutical interventions (NPIs) to reduce COVID-19 mortality and healthcare demand," Tech. rep., Imperial College London.

Ferraz, C. And F. Finan (2008): "Exposing corrupt politicians: the effects of Brazil's publicly released audits on electoral outcomes," The Quarterly journal of economics, 123, 703-745.

Fisman, R. (2001): "Estimating the value of political connections," American economic review, 91, 1095-1102.

Fisman, R. And M. Golden (2017): Corruption. What Everyone Needs to Know, Oxford University Press. 
Fluckiger, M., M. Ludwig, And A. Onder (2019): "Ebola and state legitimacy," Economic Journal, 129, 2064-2089.

Gallego, J. (2018): "Natural Disasters and Clientelism: The Case of Floods and Landslides in Colombia," Electoral Studies, 55, 73-88.

Gallego, J., G. Rivero, And J. Martinez (2019): "Preventing Rather than Punishing: An Early Warning Model of Malfeasance in Public Procurement," Mimeo.

Garret, T. And R. Sobel (2003): "The Political Economy of FEMA Disaster Payments," Economic Inquiry, 41, 496-509.

Gasper, J. And A. Reeves (2011): "Make It Rain? Retrospection and the Attentive Electorate in the Context of Natural Disasters," American Journal of Political Science, 55, 340-355.

Gonzalez-Torres, A. And E. Esposito (2017): "Epidemics and conflict: Evidence from the Ebola outbreak in Western Africa," Mimeo.

Khemani, S. (2020): "An Opportunity to Build Legitimacy and Trust in Public Institutions in the Time of COVID-19," World Bank Research and Policy Brief.

Leeson, P. And R. Sobel (2008): "Weathering Corruption," The Journal of Law and Economics, $51,667-681$.

Loayza, N. And S. Pennings (2020): "Macroeconomic Policy in the Time of COVID-19:A Primer for Developing Countries," World Bank Reserch and Policy Brief.

Ludvigson, S., S. MA, And S. NG (2020): "Covid19 and the Macroeconomic Effects of Costly Disasters," Mimeo.

Maffioli, E. (2020): "The Political Economy of Health Epidemics: Evidence from the Ebola Outbreak," Mimeo.

Martinez, L. (2019): "Sources of Revenue and Government Performance: Evidence from Colombia," Mimeo.

Mobarak, A. And Z. Barnett-Howell (2020): "Poor countries need to think twice about social distancing," Foreign Policy, 10.

Nikolova, E. And N. Marinov (2017): "Do Public Fund Windfalls Increase Corruption? Evidence From a Natural Disaster," Comparative Political Studies, 50, 1455-1488.

Olken, B. (2007): "Monitoring Corruption: Evidence from a Field Experiment in Indonesia," Journal of Political Economy, 115, 200-249.

Olken, B. And R. Pande (2012): "Corruption in Developing Countries," Annual Review of Economics, 4, 479-509.

Polley, E. C., S. Rose, And M. J. Van der LaAn (2011): "Super learning," in Targeted Learning, Springer, 43-66.

Transparencia por Colombia (2017): "Indice de Transparencia Municipal. Resultados 2015abril 2016," Tech. rep., Corporacion Transparencia por Colombia.

Transparency International (2010): "Handbook of Good Practices: Preventing Corruption in Humanitarian Operations," Tech. rep., Transparency International. 
FIGURE 1. Spatial distribution of corruption

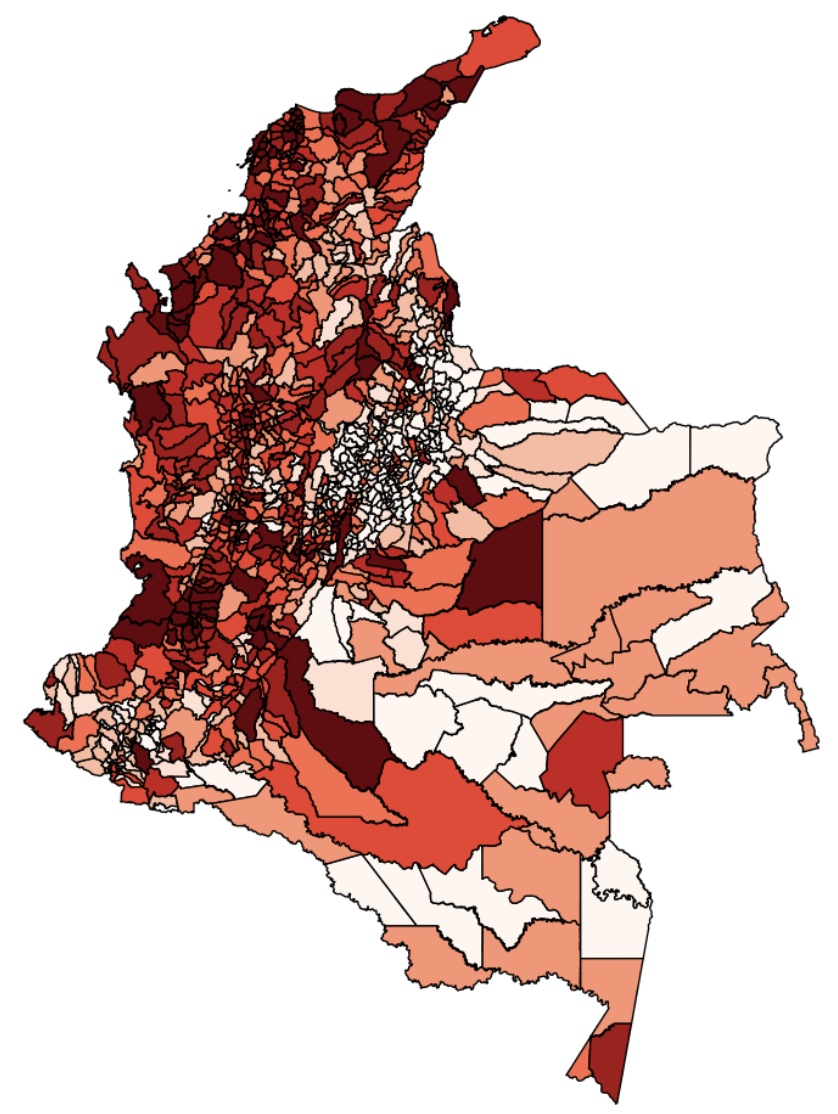

A. Corruption

Notes: This figure presents the spatial distribution of the predicted probability of corruption as discussed in Section 3.1.2. 


\section{FiguRE 2. Corruption and discretionary contracts}

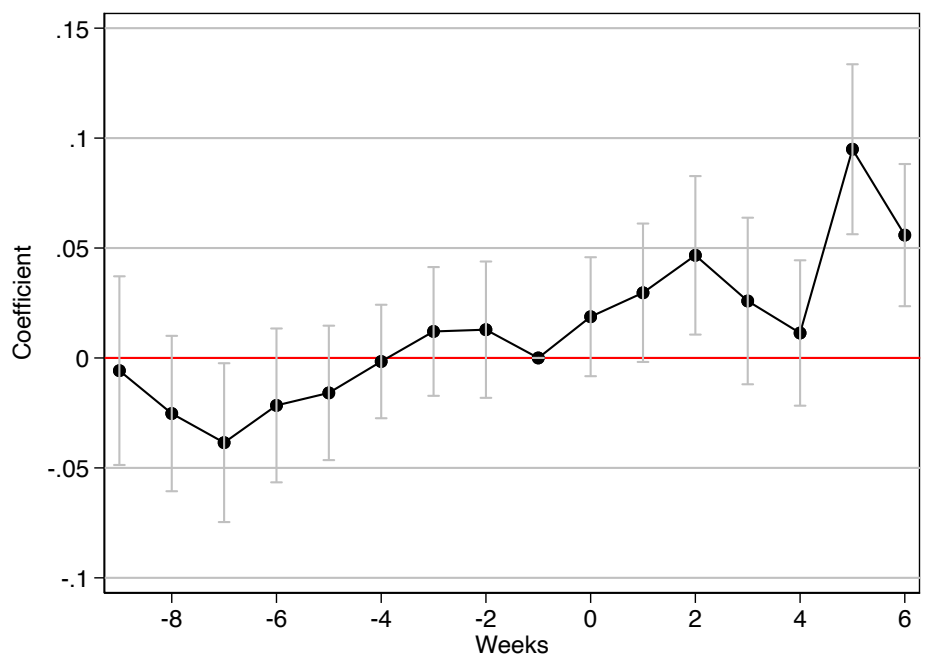

A. Any contract

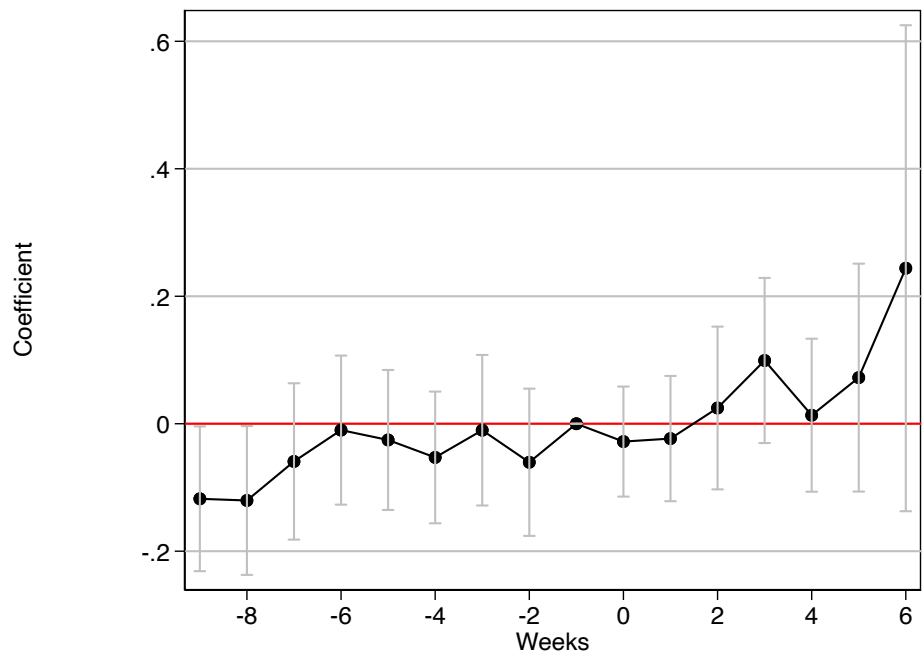

B. Ln average contract

Notes: This figure presents the coefficients from our dynamic specification presented in equation (3.2). Panel A presents the results for a dummy equal to one if there was at least one discretionary contract, while Panel B uses as dependent variable the logarithm of average amount per contract. We present the point estimates of the regression and the confidence of interval at the $95 \%$. 
TABLE 1. Corruption and discretionary contracts

\begin{tabular}{lcccccccc}
\hline \hline & $(1)$ & $\begin{array}{c}(2) \\
\text { Any contract }\end{array}$ & $(3)$ & & $\begin{array}{c}(4) \\
\text { Ln average contract amount }\end{array}$ \\
\cline { 2 - 3 } Corrupt $\times$ Post outbreak & $0.050^{* * *}$ & $0.048^{* * *}$ & $0.046^{* * *}$ & & $0.075^{* * *}$ & $0.068^{* * *}$ & $0.057^{*}$ \\
& $(0.008)$ & $(0.008)$ & $(0.008)$ & & $(0.025)$ & $(0.025)$ & $(0.029)$ \\
& & & & & & \\
Observations & 17,536 & 17,536 & 17,536 & & 11,013 & 11,013 & 11,013 \\
R-squared & 0.423 & 0.423 & 0.427 & & 0.322 & 0.322 & 0.327 \\
Municipality FE & Yes & Yes & Yes & & Yes & Yes & Yes \\
Week FE & Yes & Yes & Yes & & Yes & Yes & Yes \\
Baseline controls & Yes & Yes & Yes & & Yes & Yes & Yes \\
COVID-19 cases & No & Yes & No & & No & Yes & No \\
Market access & No & No & Yes & & No & No & Yes \\
Average dependent var & 0.729 & 0.729 & 0.729 & & 16.47 & 16.47 & 16.47 \\
\hline \hline
\end{tabular}

Notes: This table presents the results from the main specification in equation (3.1). Corrupt is a standardized version of the predicted probability of corruption. Post outbreak takes the value one after the first case of COVID-19 in Colombia. Baseline controls include population, population density, and a poverty index all of them interacted with week fixed effects. COVID-19 cases is the actual cases of COVID-19 in the municipality $m$ in week $t$. Market access include the distance to the nearest port and the distance to the department capital interacted with week fixed effect. Standard errors are computed using wild bootstrap and clustered at the municipality level. $*$ is significant at the $10 \%$ level, ${ }^{* *}$ is significant at the $5 \%$ level, *** is significant at the $1 \%$ level. 
TABLE 2. Corruption and crisis related contracts

\begin{tabular}{|c|c|c|c|c|c|c|}
\hline & (1) & $(2)$ & (3) & (4) & (5) & (6) \\
\hline & \multicolumn{2}{|c|}{ Crisis } & \multicolumn{2}{|c|}{ Food } & \multicolumn{2}{|c|}{ Health } \\
\hline Corrupt $\times$ Post outbreak & $\begin{array}{l}0.073^{*} \\
(0.046)\end{array}$ & & $\begin{array}{l}0.134^{*} \\
(0.087)\end{array}$ & & $\begin{array}{c}0.026 \\
(0.050)\end{array}$ & \\
\hline (2) Corrupt $\times$ Post 2 & & $\begin{array}{c}0.130^{* * *} \\
(0.055)\end{array}$ & & $\begin{array}{c}0.212^{* *} \\
(0.104)\end{array}$ & & $\begin{array}{c}0.055 \\
(0.063)\end{array}$ \\
\hline (1) Corrupt $\times$ Post 1 & & $\begin{array}{c}-0.044 \\
(0.047)\end{array}$ & & $\begin{array}{l}-0.118 \\
(0.087)\end{array}$ & & $\begin{array}{l}-0.020 \\
(0.050)\end{array}$ \\
\hline Observations & 5,459 & 5,459 & 2,021 & 2,021 & 4,701 & 4,701 \\
\hline R-squared & 0.438 & 0.439 & 0.611 & 0.614 & 0.413 & 0.413 \\
\hline Municipality FE & Yes & Yes & Yes & Yes & Yes & Yes \\
\hline Week FE & Yes & Yes & Yes & Yes & Yes & Yes \\
\hline Baseline controls & Yes & Yes & Yes & Yes & Yes & Yes \\
\hline Average dependent var & 16.35 & 16.35 & 16.47 & 16.47 & 16.33 & 16.33 \\
\hline pvalue difference (1) and (2) & & 0.000 & & 0.000 & & 0.170 \\
\hline
\end{tabular}

Notes: This table presents the results from the main specification in equation (3.1). The dependent variable is the logarithm of the average value of a contract. Crisis includes food and health related contracts. Corrupt is a standardize version of the predicted probability of corruption. Post outbreak takes the value one after the first case of COVID-19 in Colombia. Post 1 takes the value one between the first case of COVID-19 in Colombia and the release of a government decree relaxing public procurement requirements. Post 2 takes the value one after the release of a government decree relaxing public procurement requirements. Baseline controls include population, population density, and a poverty index all of them interacted with week fixed effects. Standard errors are computed using wild bootstrap and clustered at the municipality level. * is significant at the $10 \%$ level, $* *$ is significant at the $5 \%$ level, $* * *$ is significant at the $1 \%$ level. 


\section{Online Appendix}




\section{Figure A1. Evolution of discretionary contracts and COVID-19 cases}

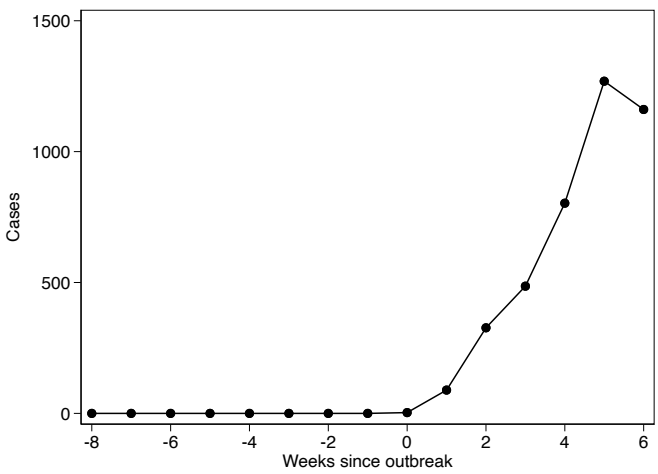

A. COVID-19 cases

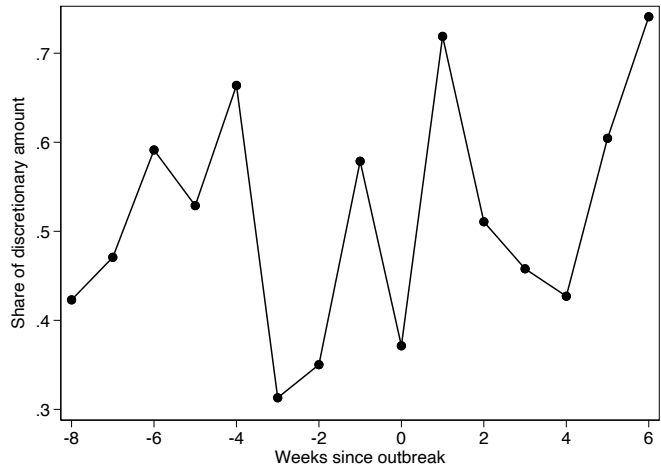

B. Share of discretionary contracts over competitive

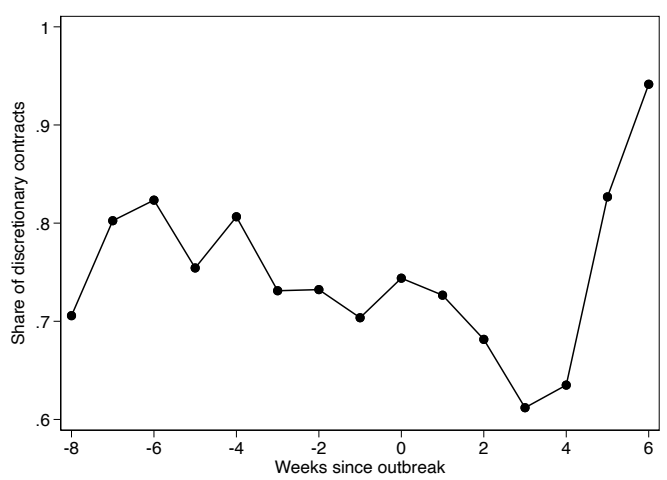

C. Share of discretionary amount over competitive

Notes: This figure presents the evolution of COVID-19 cases, share of discretionary contracts over total number of contracts and share of the amount in discretionary contracts over total value of contracts, share of discretionary contracts over discretionary and competitive, and share of the amount in discretionary contracts over total value in competitive and discretionary. 


\section{FigURE A2. Corruption and discretionary contracts: Using an alternative measure of corruption}

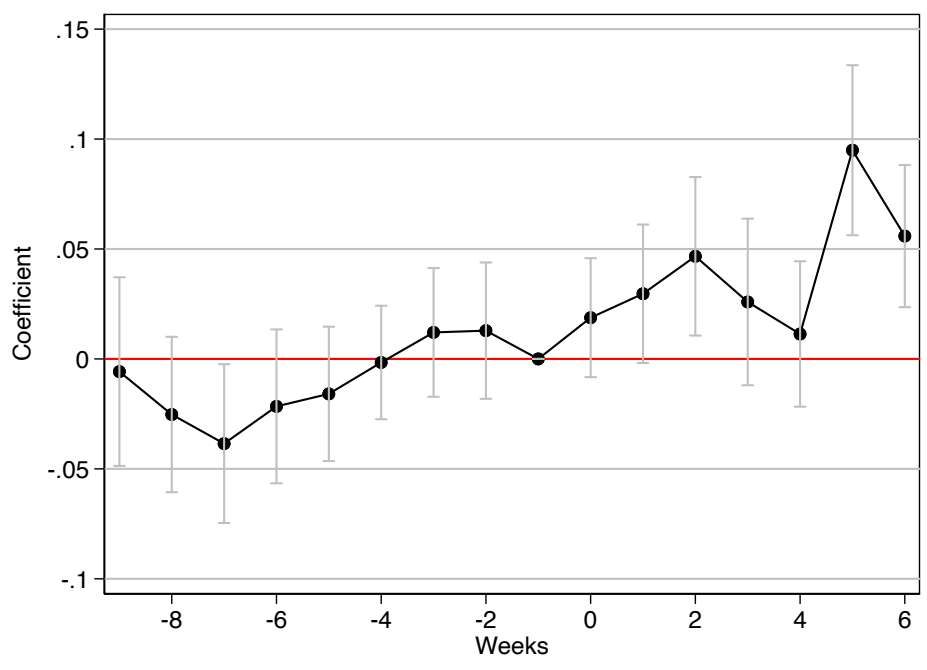

A. Any contract

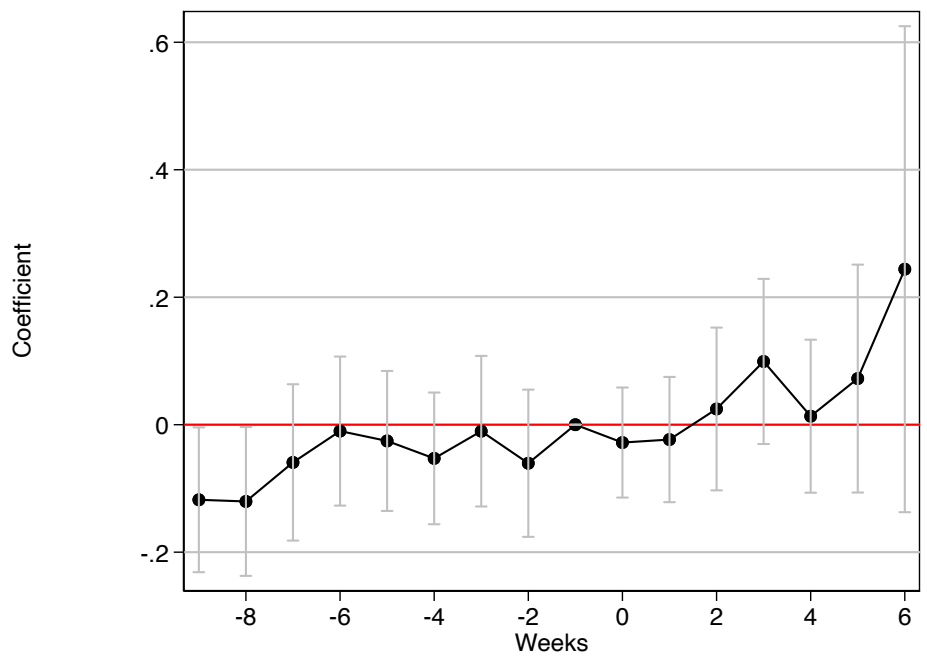

B. Ln average contract

Notes: This figure presents the coefficients from our dynamic specification presented in equation (3.2). Panel A presents the results for a dummy equal to one if there was at least one discretionary contract, while Panel B uses as dependent variable the logarithm of average amount per contract. We present the point estimates of the regression and the confidence of interval at the $95 \%$. 
Figure A3. Robustness to excluding one department at the time

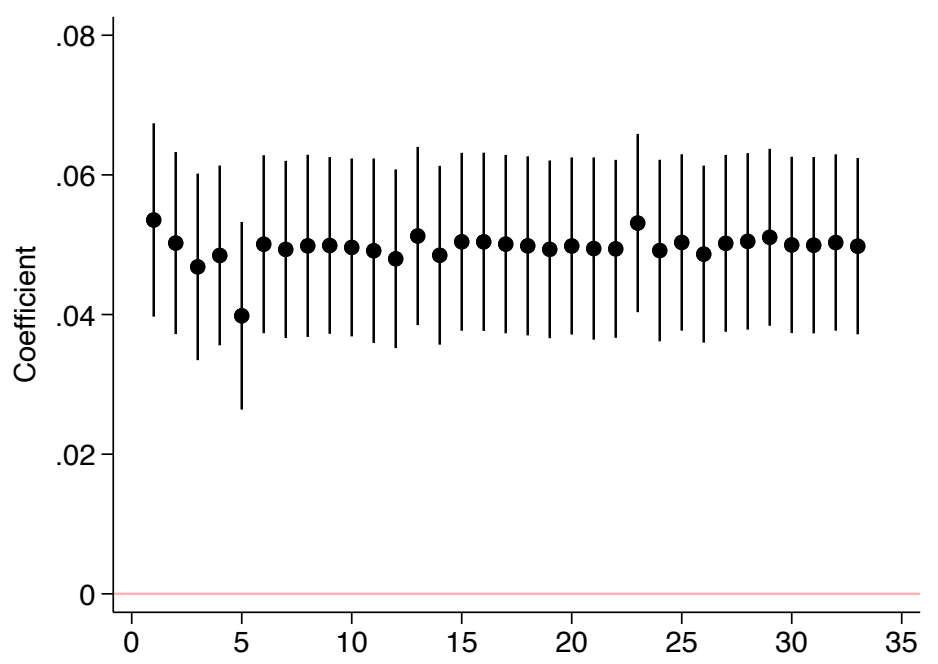

A. Any contract

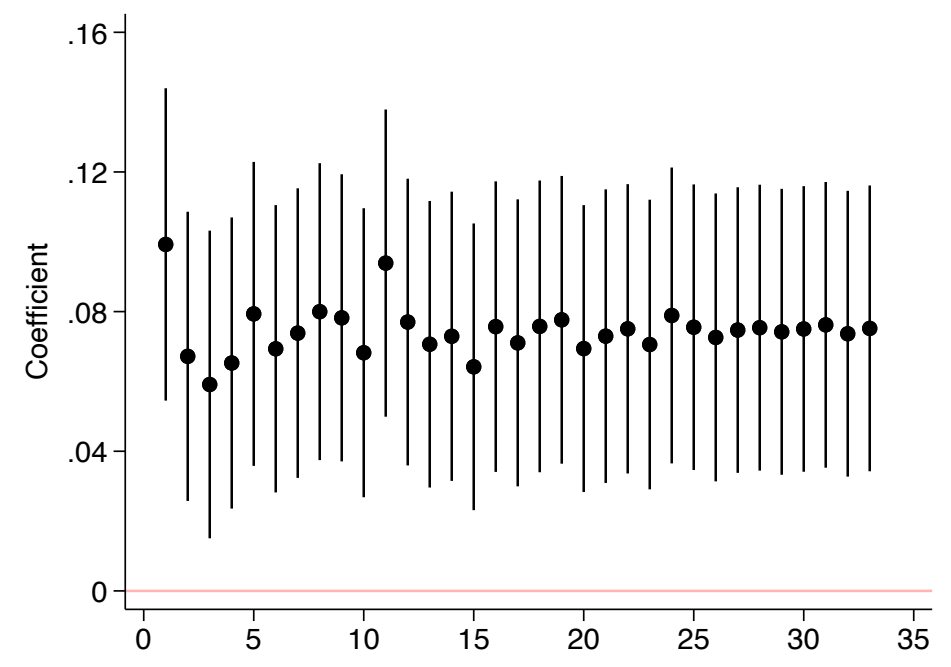

B. Ln average contract

Notes: This figure presents the robustness to excluding one department at the time and estimate the main specification (3.1). We present the point estimates of the regression and the confidence of interval at the $95 \%$. 


\section{Figure A4. Corruption and crisis related contracts}

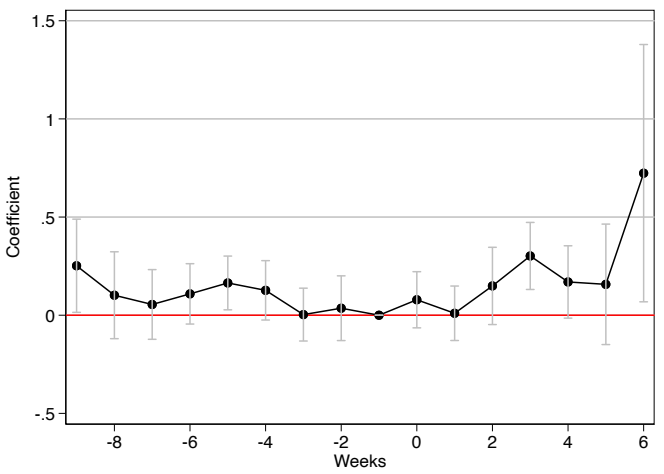

A. Ln average contract

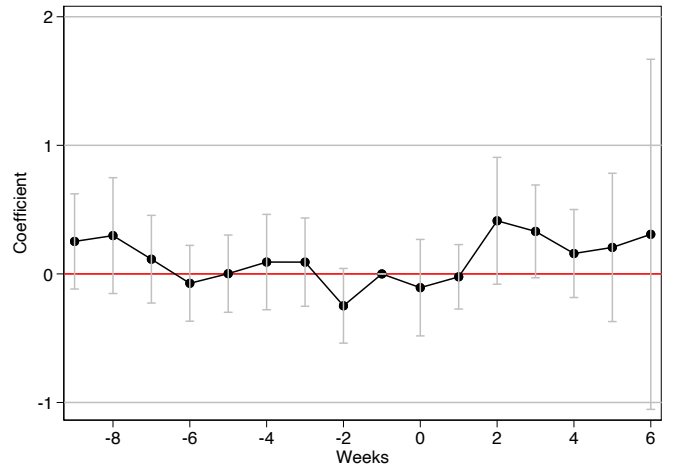

B. Ln average contract: Food

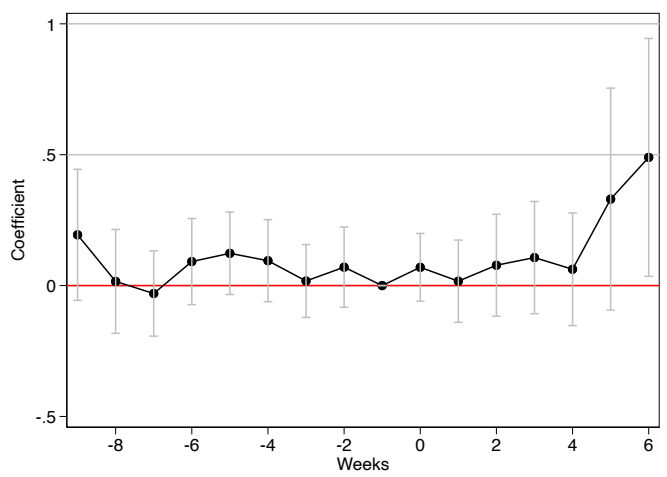

C. Ln average contract: Health

Notes: This figure presents the coefficients from our dynamic specification presented in equation (3.2). We use as dependent variable the logarithm of the average amount of a contract for different types of contracts. In Panel A we ese contracts related to food and health combined, while Panels B and C present the results for food and health related contracts separately. We present the point estimates of the regression and the confidence of interval at the $95 \%$. 


\section{Figure A5. Corruption and competitive contracts}

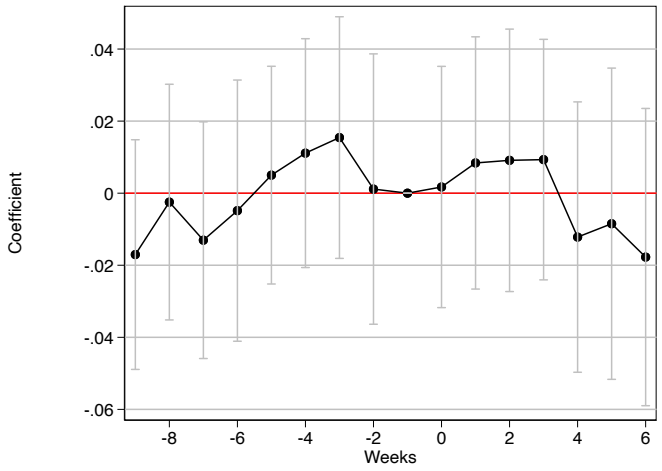

A. Any contract: Competitive

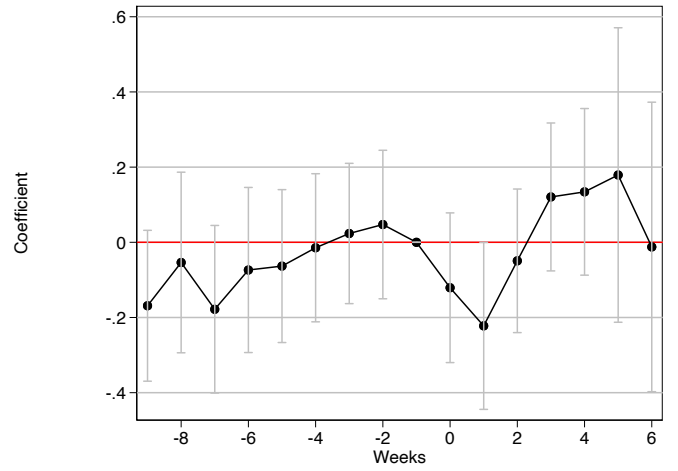

B. Ln average contract: Competitive

Notes: This figure presents the coefficients from our dynamic specification presented in equation (3.2). Panel A uses as dependent variable a dummy for at least one competitive contract, while Panel B uses as dependent variable the logarithm of the average amount of a competitive contract. We present the point estimates of the regression and the confidence of interval at the $95 \%$. 
TABle A1. Summary statistics

\begin{tabular}{|c|c|c|c|}
\hline & $(1)$ & $(2)$ & (3) \\
\hline & Mean & Median & $\begin{array}{l}\text { Standard } \\
\text { deviation }\end{array}$ \\
\hline Any discretionary contract & 0.63 & 1.00 & 0.48 \\
\hline Ln average contract value for discretionary items & 16.53 & 16.45 & 1.07 \\
\hline Ln average contract value for crisis related items & 16.56 & 16.42 & 1.23 \\
\hline Ln average contract value for food items & 16.95 & 16.80 & 1.47 \\
\hline Ln average contract value for health items & 16.41 & 16.31 & 1.13 \\
\hline Any competitive contract & 0.34 & 0.00 & 0.47 \\
\hline Ln average contract value for competitive items & 16.58 & 16.32 & 1.74 \\
\hline Predicted probability of corruption & 0.20 & 0.18 & 0.10 \\
\hline
\end{tabular}

Notes: This table presents summary statistics for the main variables used in the empirical analysis. 
TABle A2. Corruption and COVID-19 exposure

\begin{tabular}{lccc}
\hline \hline & $\begin{array}{c}(1) \\
\text { Total }\end{array}$ & $\begin{array}{c}\text { Total } \\
\text { cases }\end{array}$ & deaths \\
& & \\
& -2.528 & & -0.061 \\
Corrupt & $(1.700)$ & & $(0.168)$ \\
& & \\
Observations & 1,090 & & 1,090 \\
R-squared & 0.753 & & 0.514 \\
Department FE & Yes & & Yes \\
Baseline controls & Yes & Yes \\
Average dependent var & 4.896 & 0.220 \\
\hline \hline
\end{tabular}

Notes: This table presents the results from the main specification in equation (3.1). Corrupt is a standardize version of the predicted probability of corruption. Baseline controls include population, population density, and a poverty index all of them interacted with week fixed effects. Standard errors are computed using wild bootstrap. $*$ is significant at the $10 \%$ level, $* *$ is significant at the $5 \%$ level, *** is significant at the $1 \%$ level. 
TABLE A3. Corruption, discretionary contracts, and policy response to COVID-19

\begin{tabular}{|c|c|c|}
\hline & $\begin{array}{c}(1) \\
\text { Any } \\
\text { contract }\end{array}$ & $\begin{array}{c}(2) \\
\text { Ln average } \\
\text { contract }\end{array}$ \\
\hline (2) Corrupt $\times$ Post 2 & $\begin{array}{c}0.056^{* * *} \\
(0.009)\end{array}$ & $\begin{array}{c}0.107^{* * *} \\
(0.032)\end{array}$ \\
\hline (1) Corrupt SL $\times$ Post 1 & $\begin{array}{c}0.034^{* * *} \\
(0.010)\end{array}$ & $\begin{array}{c}0.023 \\
(0.028)\end{array}$ \\
\hline Observations & 17,536 & 11,013 \\
\hline R-squared & 0.424 & 0.322 \\
\hline Municipality FE & Yes & Yes \\
\hline Week FE & Yes & Yes \\
\hline Baseline controls & Yes & Yes \\
\hline Average dependent var & 0.729 & 16.47 \\
\hline pvalue difference (1) and (2) & 0.060 & 0.040 \\
\hline
\end{tabular}

Notes: This table presents the results from the main specification in equation (3.1). Corrupt is a standardize version of the predicted probability of corruption. Post 1 takes the value one between the first case of COVID-19 in Colombia and the release of a government decree relaxing public procurement requirements. Post 2 takes the value one after the release of a government decree relaxing public procurement requirements. Baseline controls include population, population density, and a poverty index all of them interacted with week fixed effects. Standard errors are computed using wild bootstrap and clustered at the municipality level. ${ }^{*}$ is significant at the $10 \%$ level, ${ }^{* *}$ is significant at the $5 \%$ level, ${ }^{* * *}$ is significant at the $1 \%$ level. 


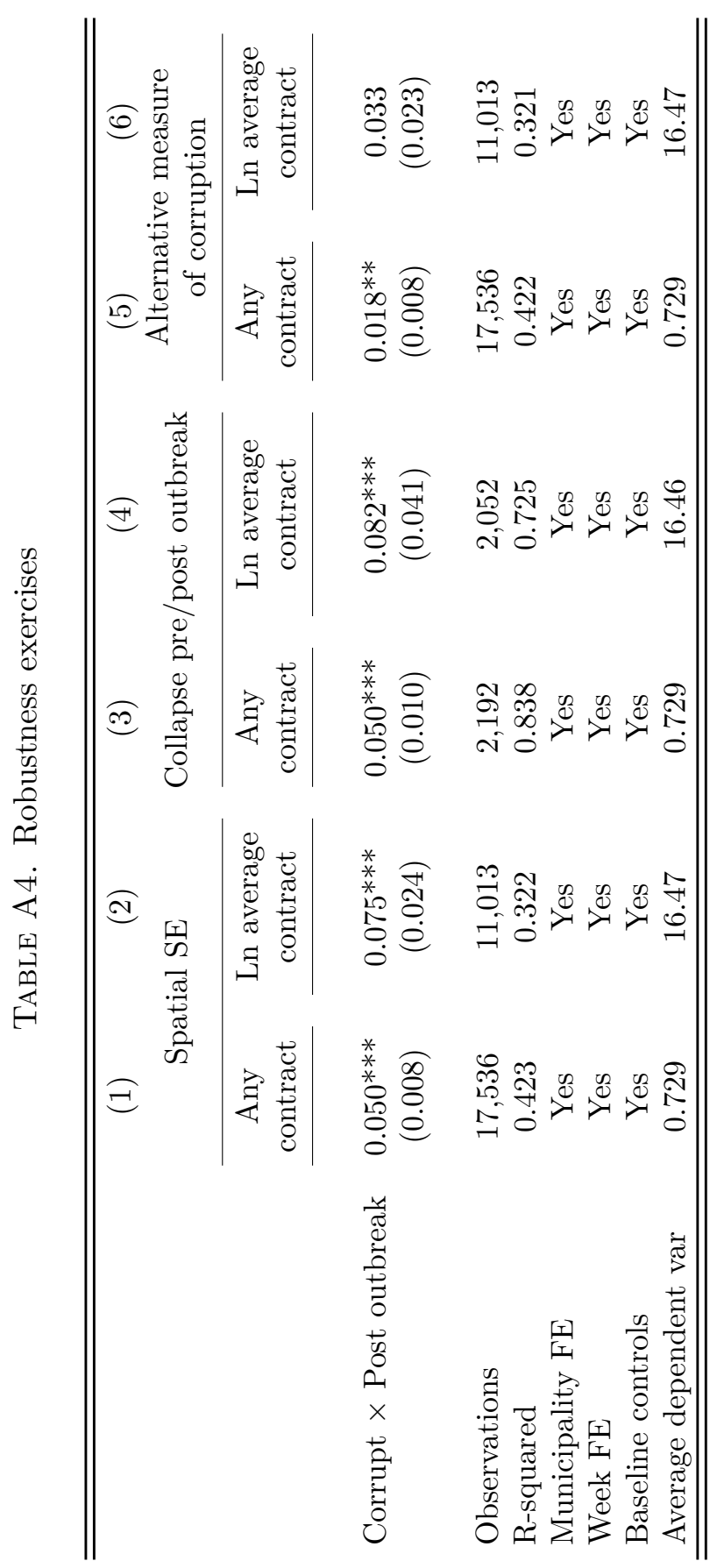

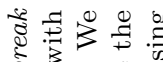

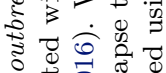

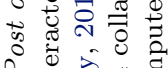

Q.

ㅎำ

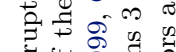

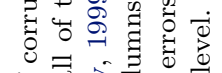

पे बै

贾.

元

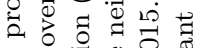

뭉

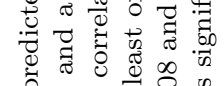

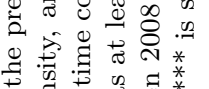

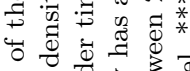

宕 :

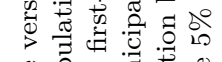

兽

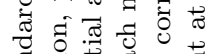

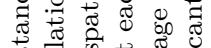

क

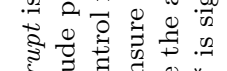

है

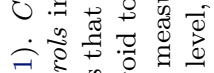

कि है हैं

范势

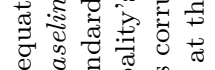

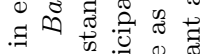

효 워

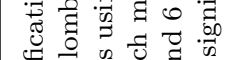

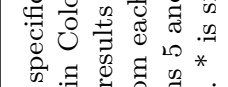

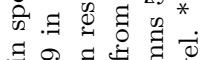

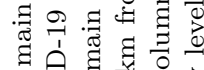

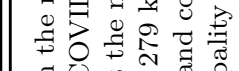

घี 0 눙

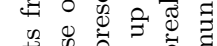

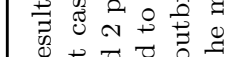

o

प)

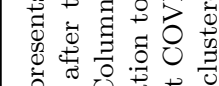

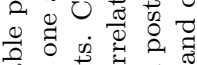

ฐ

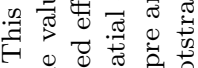

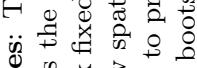

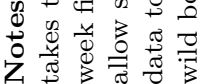


TABLE A5. Corruption and competitive contracts

\begin{tabular}{lccc}
\hline \hline & $(1)$ & & $(2)$ \\
& $\begin{array}{c}\text { Any } \\
\text { contract }\end{array}$ & & $\begin{array}{c}\text { Ln average } \\
\text { contract amount }\end{array}$ \\
\cline { 2 - 2 } Corrupt $\times$ Post outbreak & -0.001 & & 0.026 \\
& $(0.008)$ & & $(0.049)$ \\
& & & \\
Observations & 17,536 & & 6,026 \\
R-squared & 0.546 & & 0.521 \\
Municipality FE & Yes & & Yes \\
Week FE & Yes & & Yes \\
Baseline controls & Yes & & Yes \\
Average dependent var & 0.411 & & 16.54 \\
\hline \hline
\end{tabular}

Notes: This table presents the results from the main specification in equation (3.1). Corrupt is a standardize version of the predicted probability of corruption. Post outbreak takes the value one after the first case of COVID-19 in Colombia. Baseline controls include population, population density, and a poverty index all of them interacted with week fixed effects. Standard errors are computed using wild bootstrap and clustered at the municipality level. * is significant at the $10 \%$ level, ** is significant at the $5 \%$ level, $* * *$ is significant at the $1 \%$ level. 